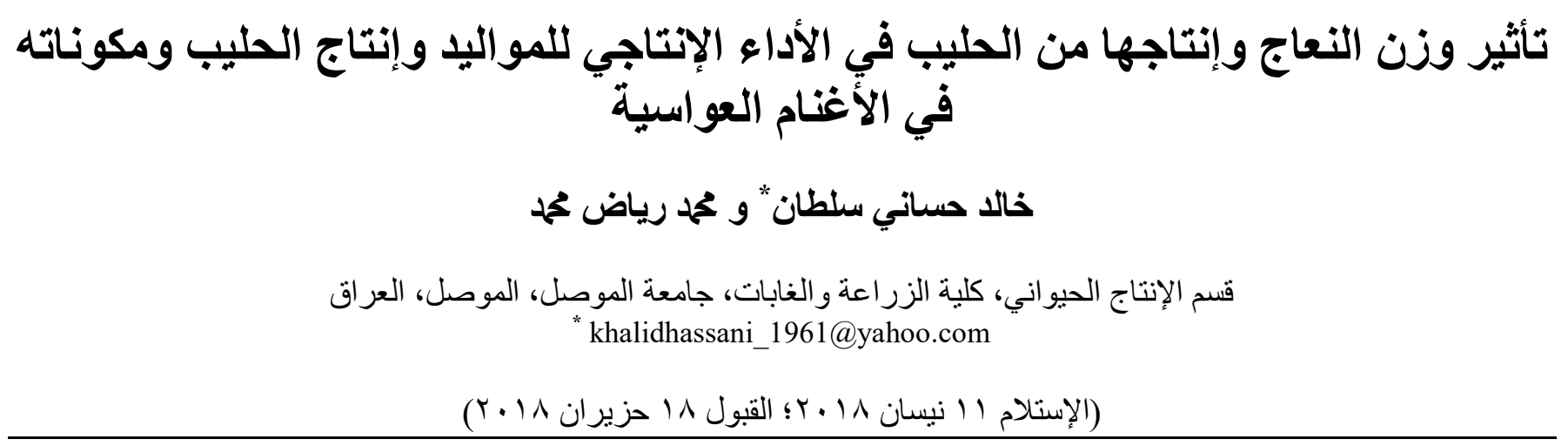

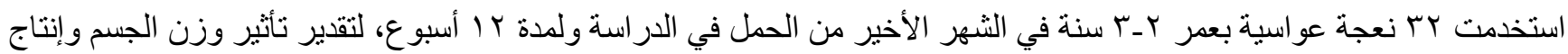

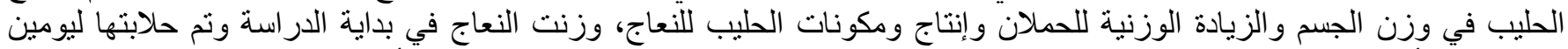

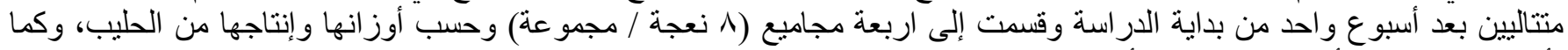

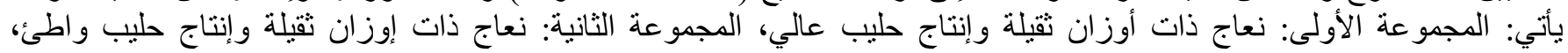

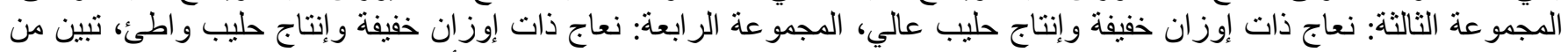

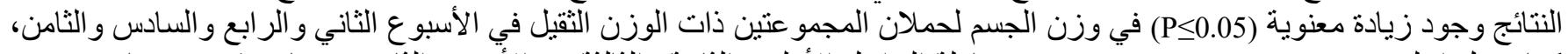

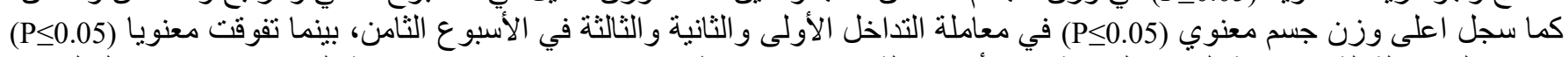

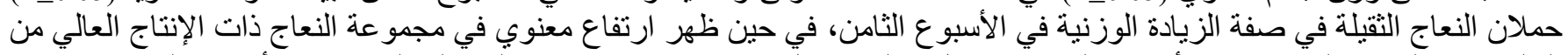

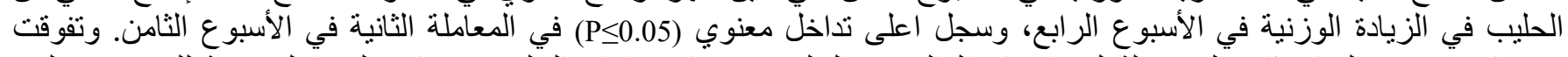

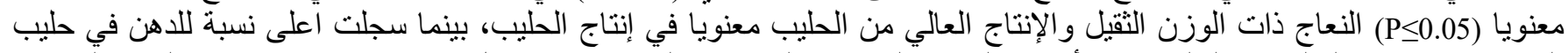

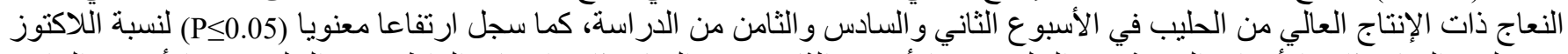

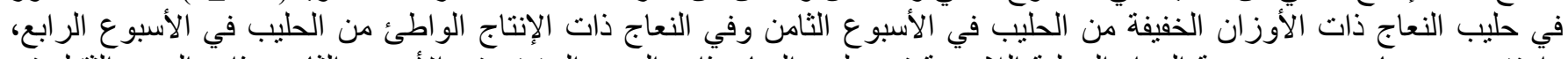

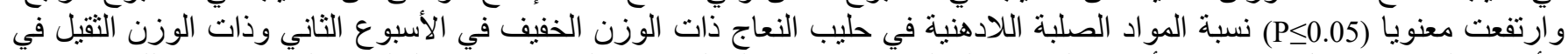

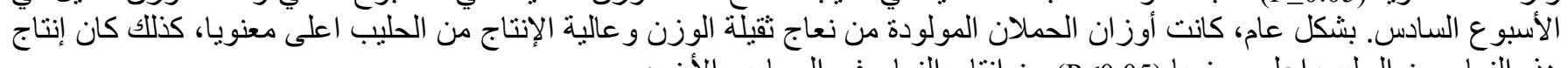

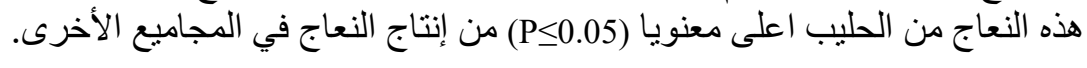

\title{
Effect of body weight of ewes and milk yield in productive performance of lambs, milk yield and components of Awassi sheep
}

\section{KH. H. Sultan and R.M. Mohammed}

\author{
Animal Production Department, College of Agriculture and Forestry, Mosul University, Mosul, Iraq
}

\begin{abstract}
In the current study, 32 Awassi ewes $2-3$ years aged were used with their lambs for 12 weeks, to evaluate the effect of Body Weight (BW) and Milk Yield (MY) on Body weight BW, Body Weight Gain (BWG), MY and milk components. After lambing, ewes were weighted directly, then at the $1^{\text {st }}$ week of lambing, ewes were milked for 2 consecutive days, in order to determine the milk yield, Ewes divided randomly to 4 groups depending on their body weights and milk yield, the groups were: $1^{\text {st }}$ group: ewes with high BW and high MY, $2^{\text {nd }}$ group: ewes with high BW and law MY, $3^{\text {rd }}$ group: ewes with low BW and high MY, $4^{\text {th }}$ group: ewes with low BW and low MY. The result showed a significant increase $(\mathrm{P} \leq 0.05)$ in $\mathrm{BW}$ in heavy ewes (HE) groups at the $2^{\text {nd }}, 4^{\text {th }}, 6^{\text {th }}$ and $8^{\text {th }}$ weeks, the best significant interactions $(\mathrm{P} \leq 0.05)$ were recorded in the $1^{\text {st }}, 2^{\text {nd }}$ and $3^{\text {rd }}$ group at $8^{\text {th }}$ weeks. Also, there is a significant increase $(\mathrm{P} \leq 0.05)$ in BWG in the HE at $8^{\text {th }}$ week. The effect of MY was evident in milk production, MY of HW and high milk (HM) increased significantly at the $2^{\text {nd }}, 4^{\text {th }}, 6^{\text {th }}$ and $8^{\text {th }}$ weeks. Also a significant
\end{abstract}


increase $(\mathrm{P} \leq 0.05)$ in milk fat $\%$ in $\mathrm{HM}$ ewes at $2^{\text {nd }}, 6^{\text {th }}$ and $8^{\text {th }}$ weeks after lambing. On other hand the results revealed a significant increase $(\mathrm{p} \leq 0.05)$ in lactose $\%$ in Light Ewes Milk (LE) at $8^{\text {th }}$ week and Low Milk Ewes (LOM) at $4^{\text {th }}$ week, also solid non-fat components \% increased significantly in LE at $2^{\text {nd }}$ week and HW ewes. In conclusion, the body weight of the lambs that born from the ewes with (heavy weight and high milk production) were significantly higher than other lambs, also, milk production of these ewes was significantly $(\mathrm{P} \leq 0.05)$ higher than other groups.

Available online at http://www.vetmedmosul.org/ijvs

\section{المواد وطرائق العمل}

المقدمة

أجريت هذه الاراسة في حقل خاص في قرية بايبوخت

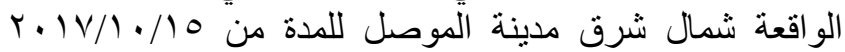

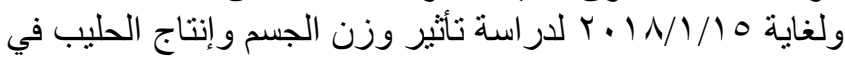

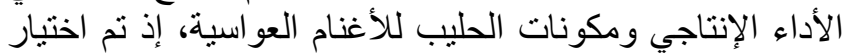

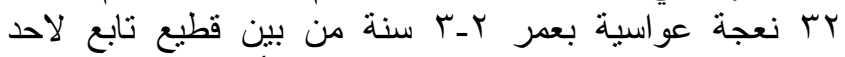

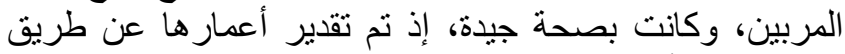

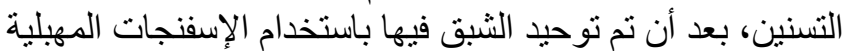

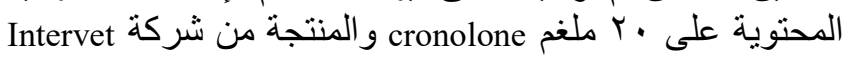

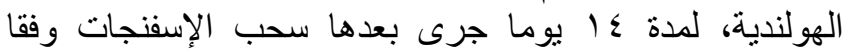

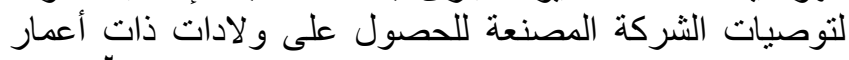

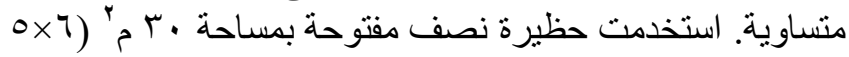

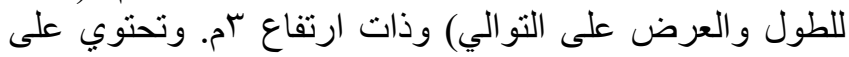

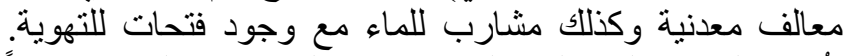

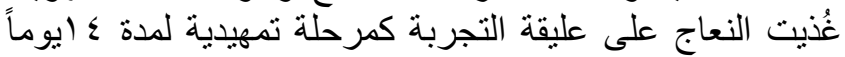

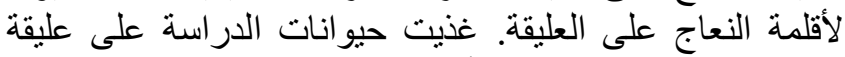

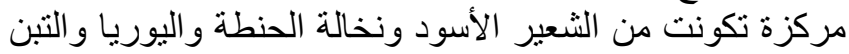

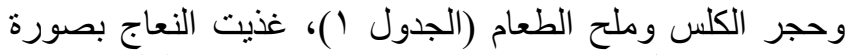

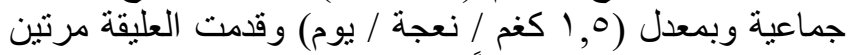

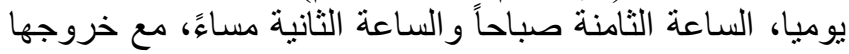

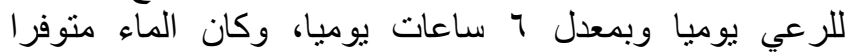

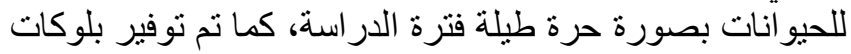

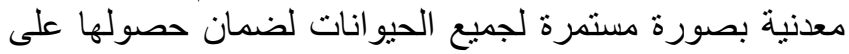

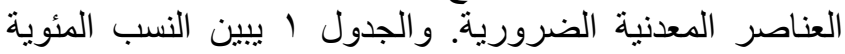

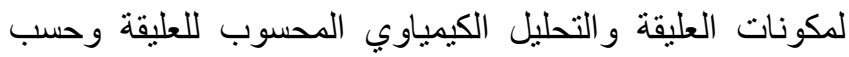

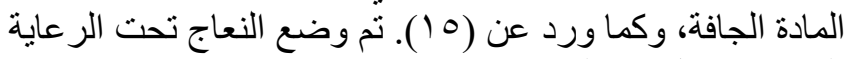

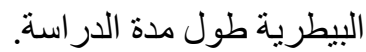
وزنت النعاج و الو لادات بداية الدر اسة، ولغرض العاد إكمال توزيع

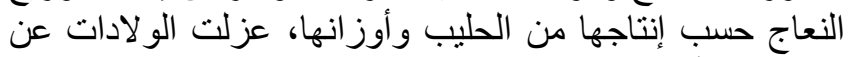

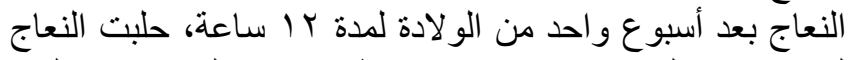

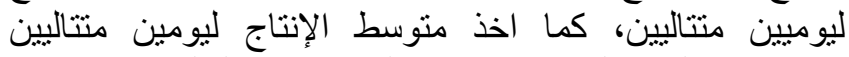

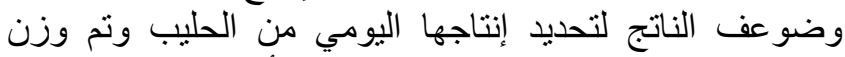

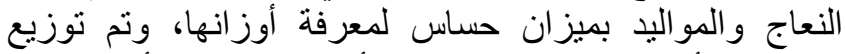

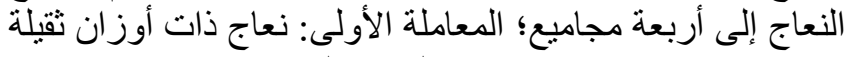

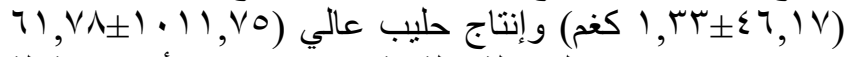

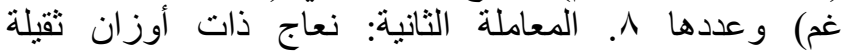

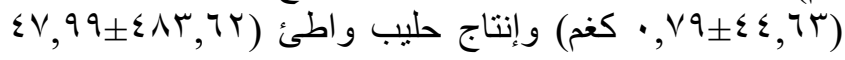

إن الأغنام العواسية هي السلالة الأكثر أهمية في الأراضي

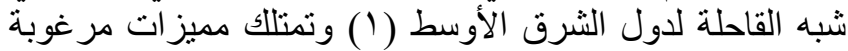

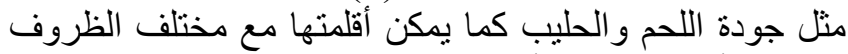

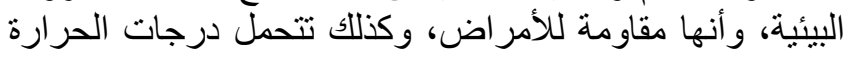

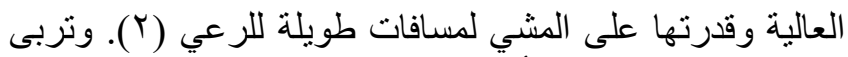
هذه السلالة في العراق أسأسا لغرض العافي إنتاج اللحوم من الحملان و الكباش (r).

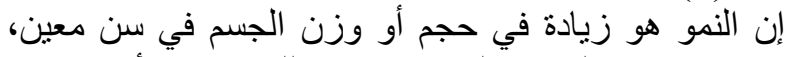

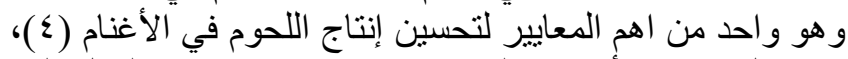

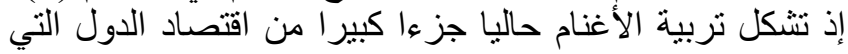

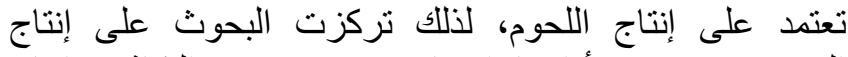

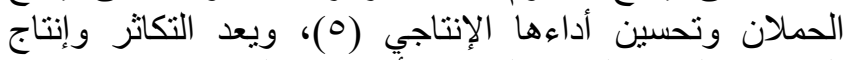

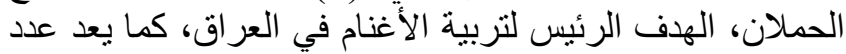

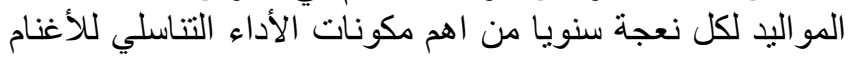

إن سد حاجة الأسواق من اللحوم تتم عن طريق زيادة نسبة

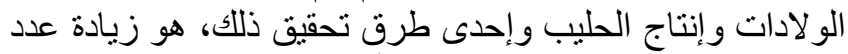

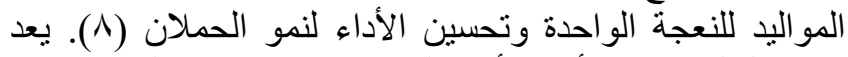

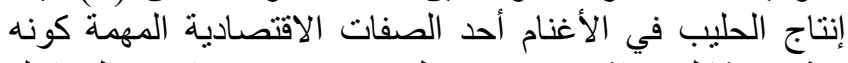

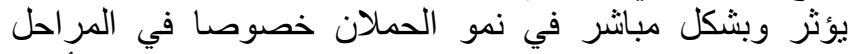

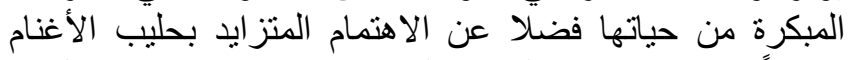

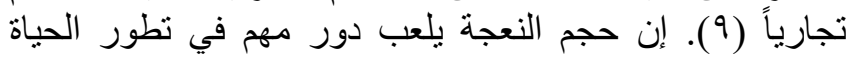

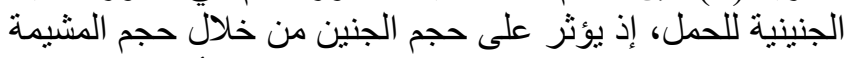

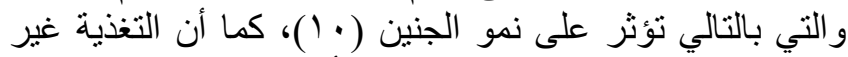

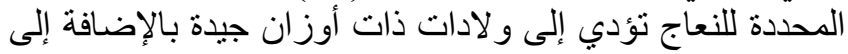

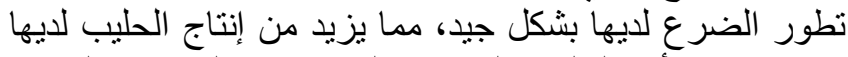

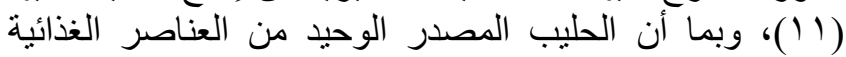

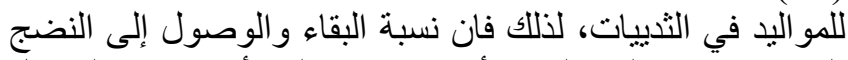

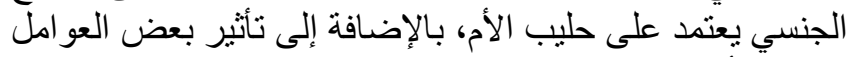

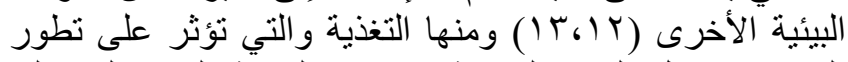

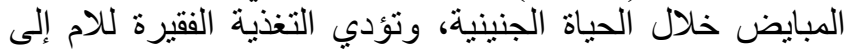

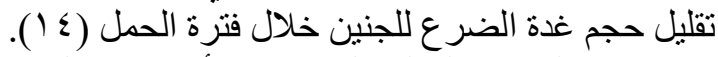

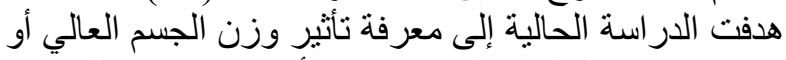

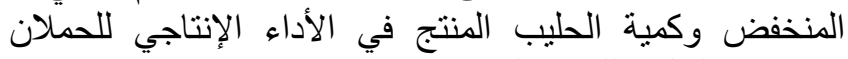
ومكونات الحليب للنعاج العو اسية. 


\section{النتائج}

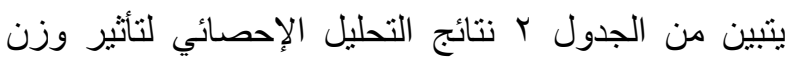

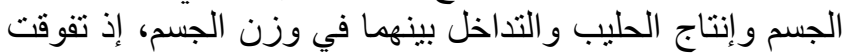

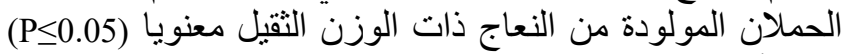

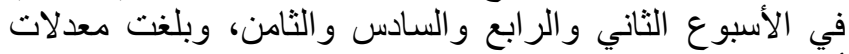

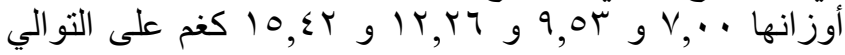

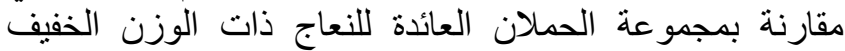

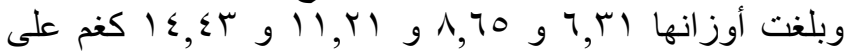
التوالي، بينما سجل افضل تداخل لوزن الجن الجسم في المعاملة الثانية

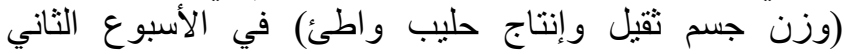

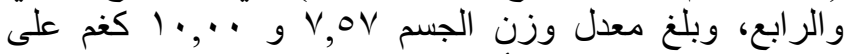

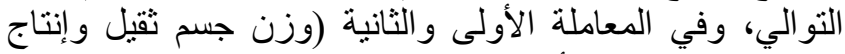

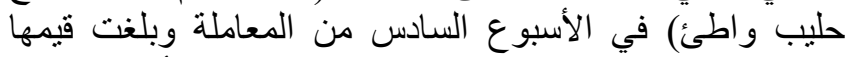

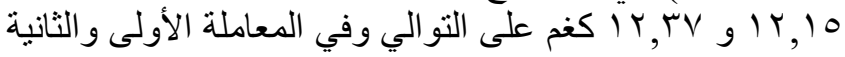

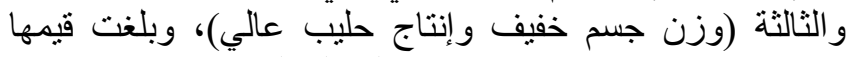

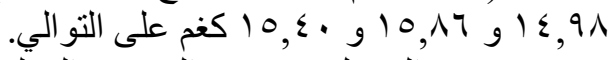

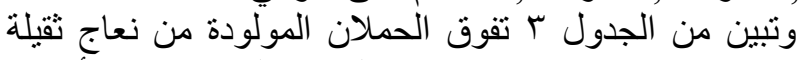

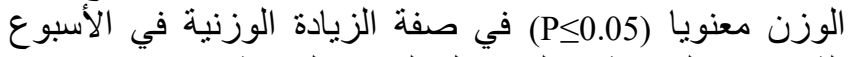

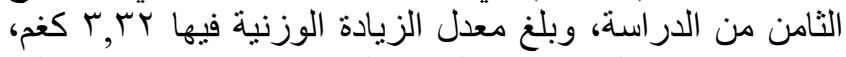

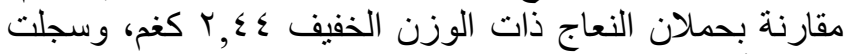

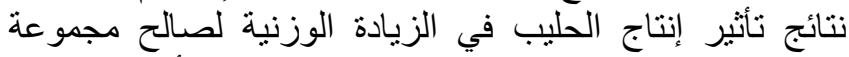

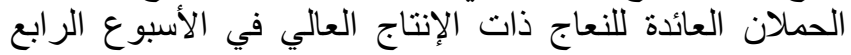

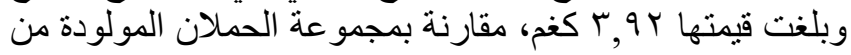

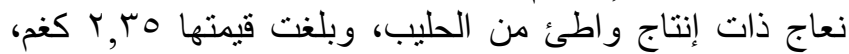

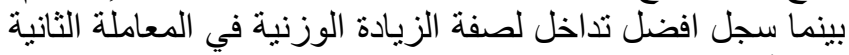

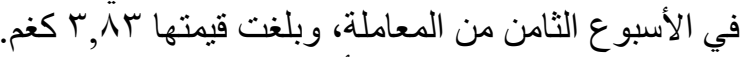

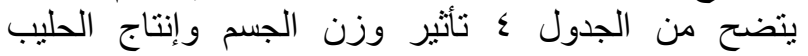

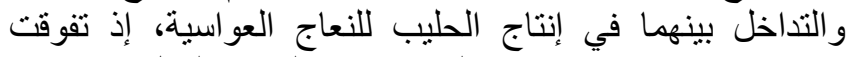

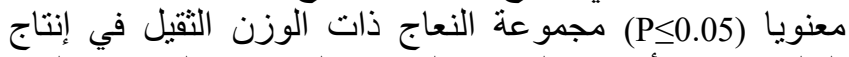

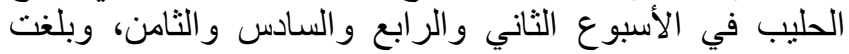

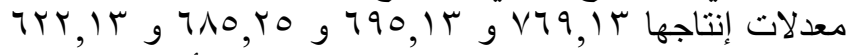

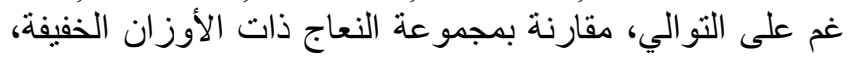

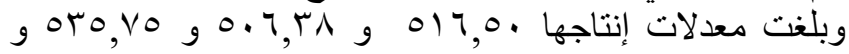

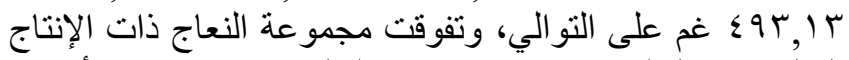

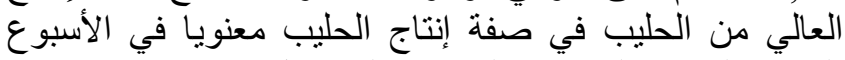

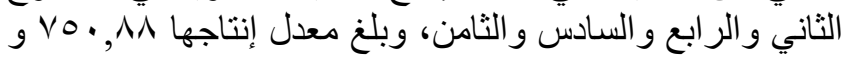

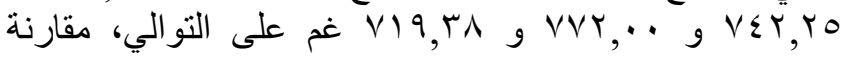

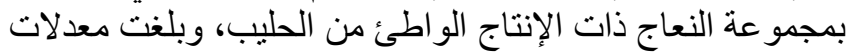

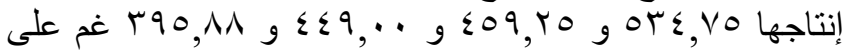

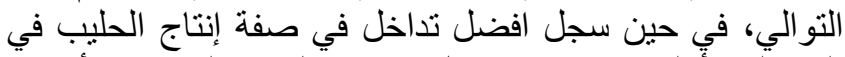

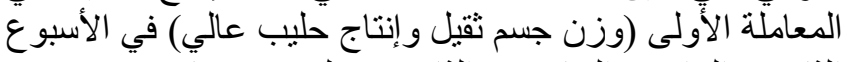

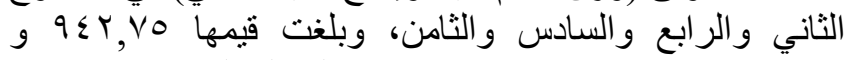
.

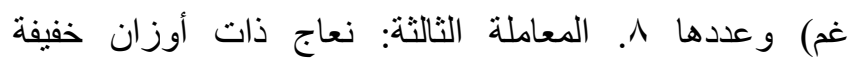

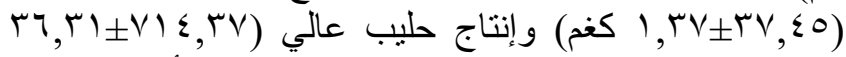

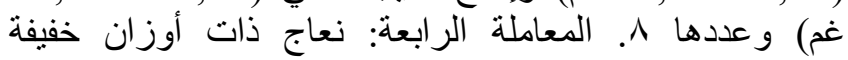

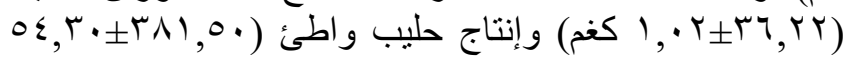

غم) و عددها $\wedge$.

الجدول ا: النسب المئوية لمكونات العليقة والتحليل الكيمياوي

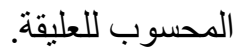

\begin{tabular}{|c|c|c|c|c|}
\hline $\begin{array}{l}\text { الخام \% } \\
\text { البروتين }\end{array}$ & $\begin{array}{c}\text { الجادة } \\
\text { المادة } \\
\text { \% }\end{array}$ & الأيضية & فسبتها & المــــــادة \\
\hline 7,97 & $7 \cdot, T_{0}$ & 1Vo. & 70 & شعير \\
\hline $11,1$. & $r \leqslant, T 0$ & Tr. & TV & نخالة الحنطة \\
\hline$\cdot, 10$ & $7, \leqslant 0$ & $V \vee, q$. & 7 & تبن \\
\hline$r, \wedge)$ & $\cdot, 90$ & - & 1 & يوريا \\
\hline - & $\cdot, r_{0}$ & - & $\cdot, 0$ & ملح \\
\hline - & $\cdot, T_{0}$ & - & $\cdot, 0$ & حجر الكلس \\
\hline $1 \varepsilon, \cdot \varepsilon$ & $9 r, \wedge 0$ & $r \leq \varepsilon \wedge$ & $1 \ldots$ & المجموع \\
\hline
\end{tabular}

وزنت الحملان كل أسبوعين للتعرف على الزيادة الوزنية

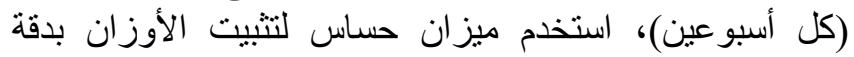

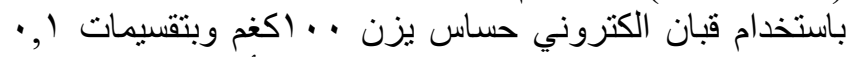

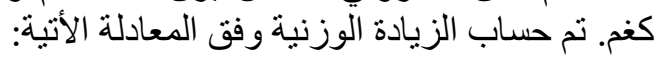
الزيادة الوزنية (كغم)= الوزن اللاحق - الوزن السابق

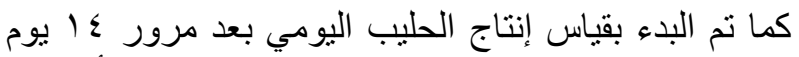

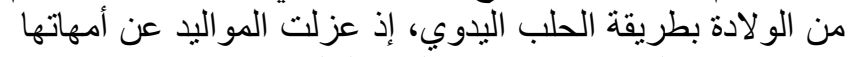

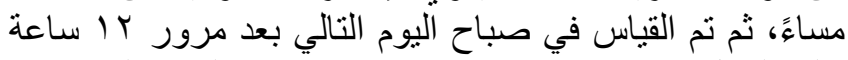

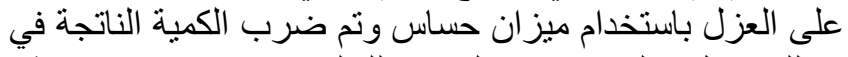

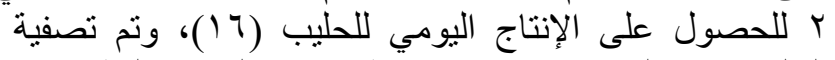

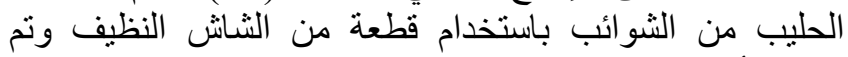

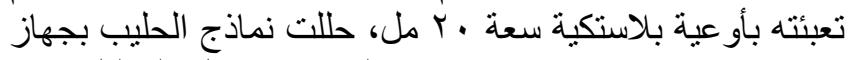
Funke Gerber Analyzer الدهن و البروتين و اللاكتوز و المواد الصلبة اللادهنية.

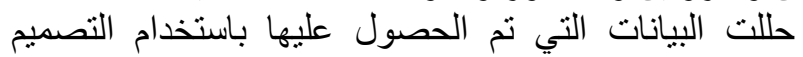

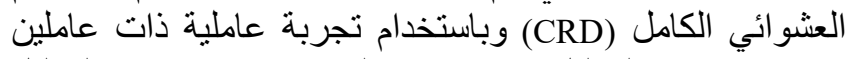

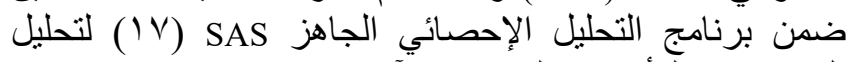
البيانات وفقا للأنموذج الرياضي الآتي:

$Y i j k l=\mu+B i+M j+B M i j+B M j k+e i j k$

و لاختبار معنوية الفروق بين المتوسطات، فقد استخدم اختبار

دنكن متعدد الحدود (1) (1) ). 
الجدول r : المتوسط د الخطأ القياسي لتأثير وزن الجسم و إنتاج الحليب والتداخل بينهما في وزن الجسم (كغم) للحملان العواسية

\begin{tabular}{|c|c|c|c|c|c|}
\hline \multicolumn{5}{|c|}{ الصفات } & \multirow{2}{*}{ المعاملات } \\
\hline الأسبوع الثامن & الأسبوع السادس & الأسبوع الرابع & الأسبوع الثاني & الوزن عند الولادة & \\
\hline \multicolumn{6}{|c|}{ تأثثير وزن الجسم } \\
\hline $0.24 \pm 15.42 \mathrm{a}$ & $0.21 \pm 12.26 \mathrm{a}$ & $0.16 \pm 9.53 \mathrm{a}$ & $0.22 \pm 7.00 \mathrm{a}$ & $0.16 \pm 4.68 \mathrm{a}$ & ثقيل \\
\hline $0.34 \pm 14.43 \mathrm{~b}$ & $0.19 \pm 11.21 \mathrm{~b}$ & $0.17 \pm 8.65 b$ & $0.18 \pm 6.31 \mathrm{~b}$ & $0.23 \pm 4.26 \mathrm{a}$ & خفيف \\
\hline \multicolumn{6}{|c|}{ تأثثر إنتاج الحليب } \\
\hline $0.22 \pm 15.19 \mathrm{a}$ & $0.21 \pm 12.01 \mathrm{a}$ & $0.09 \pm 9.08 \mathrm{a}$ & $0.13 \pm 6.57 \mathrm{a}$ & $0.17 \pm 4.44 a$ & \\
\hline $0.38 \pm 14.66 \mathrm{a}$ & $0.25 \pm 11.46 \mathrm{a}$ & $0.27 \pm 9.10 \mathrm{a}$ & $0.28 \pm 6.73 \mathrm{a}$ & $0.24 \pm 4.50 \mathrm{a}$ & \\
\hline \multicolumn{6}{|c|}{ تأثثير التداخل بين وزن الجسم و إنتاج الحليب } \\
\hline $0.34 \pm 14.98 \mathrm{a}$ & $0.43 \pm 12.15 \mathrm{a}$ & $0.15 \pm 9.06 \mathrm{~b}$ & $0.16 \pm 6.42 \mathrm{~b}$ & $0.24 \pm 4.46 \mathrm{a}$ & 1 \\
\hline $0.30 \pm 15.86 \mathrm{a}$ & $0.12 \pm 12.37 \mathrm{a}$ & $0.18 \pm 10.00 \mathrm{a}$ & $0.31 \pm 7.57 \mathrm{a}$ & $0.21 \pm 4.91 \mathrm{a}$ & 2 \\
\hline $0.31 \pm 15.40 \mathrm{a}$ & $11 . \pm 11.88 \mathrm{~b}$ & $0.11 \pm 9.10 b$ & $0.20 \pm 6.72 b$ & $0.26 \pm 4.42 \mathrm{a}$ & 3 \\
\hline $0.37 \pm 13.47 \mathrm{~b}$ & $0.16 \pm 10.00 \mathrm{~b}$ & $0.25 \pm 8.21 \mathrm{~b}$ & $0.23 \pm 5.90 \mathrm{~b}$ & $0.40 \pm 4.10 \mathrm{a}$ & 4 \\
\hline
\end{tabular}

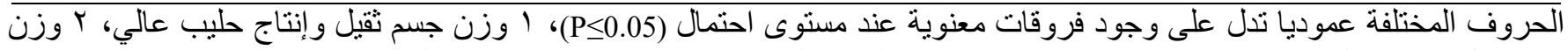

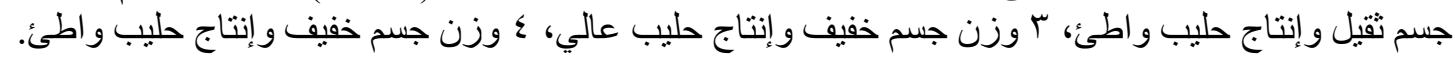

الجدول r: المتوسط 土 الخطأ القياسي لتأثير وزن الجسم و إنتاج الحليب و التداخل بينهما في الزيادة الوزنية (كغم) للحملان العو اسية

\begin{tabular}{|c|c|c|c|c|c|}
\hline \multicolumn{5}{|c|}{ الصفات } & \multirow{2}{*}{ المعاملات } \\
\hline 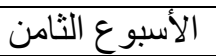 & الأسبوع السادس & الأسبوع الر ابع & الأسبوع الثاني & الوزن عند الولادة & \\
\hline & & & & & تأثثير وزن الجسم \\
\hline $0.25 \pm 3.32 \mathrm{a}$ & $0.21 \pm 3.16 \mathrm{a}$ & $0.24 \pm 2.73 \mathrm{a}$ & $0.20 \pm 2.53 \mathrm{a}$ & $0.20 \pm 2.31 \mathrm{a}$ & ثقيل \\
\hline $0.19 \pm 2.44 \mathrm{~b}$ & $0.19 \pm 3.21 \mathrm{a}$ & $0.13 \pm 2.56 \mathrm{a}$ & $0.14 \pm 2.34 \mathrm{a}$ & $0.21 \pm 2.05 \mathrm{a}$ & خفيف \\
\hline & & & & & تأثنير إنتاج الحليب \\
\hline $0.21 \pm 2.69 \mathrm{a}$ & $0.22 \pm 3.17 \mathrm{a}$ & $0.22 \pm 2.93 \mathrm{a}$ & $0.19 \pm 2.50 \mathrm{a}$ & $0.19 \pm 2.13 \mathrm{a}$ & عالي ع ع \\
\hline $0.28 \pm 3.06 \mathrm{a}$ & $0.18 \pm 3.20 \mathrm{a}$ & $0.12 \pm 2.35 \mathrm{~b}$ & $0.16 \pm 2.36 \mathrm{a}$ & $0.23 \pm 2.23 \mathrm{a}$ & و اطنئ \\
\hline & & & & \multicolumn{2}{|c|}{ تأتثير التداخل بين وزن الجسم و إنتاج الحليب } \\
\hline $0.36 \pm 2.81 \mathrm{~b}$ & $0.34 \pm 2.83 \mathrm{a}$ & $0.44 \pm 3.08 \mathrm{a}$ & $0.27 \pm 2.63 \mathrm{a}$ & $0.20 \pm 1.96 \mathrm{a}$ & 1 \\
\hline $0.27 \pm 3.83 \mathrm{a}$ & $0.23 \pm 3.48 \mathrm{a}$ & $0.15 \pm 2.37 \mathrm{a}$ & $0.31 \pm 2.42 \mathrm{a}$ & $0.32 \pm 2.66 \mathrm{a}$ & 2 \\
\hline $0.25 \pm 2.58 \mathrm{~b}$ & $0.26 \pm 3.51 \mathrm{a}$ & $0.13 \pm 2.78 \mathrm{a}$ & $0.27 \pm 2.37 \mathrm{a}$ & $0.32 \pm 2.30 \mathrm{a}$ & 3 \\
\hline $0.30 \pm 2.30 \mathrm{~b}$ & $0.25 \pm 2.92 \mathrm{a}$ & $0.20 \pm 2.33 \mathrm{a}$ & $0.12 \pm 2.30 \mathrm{a}$ & $0.28 \pm 1.80 \mathrm{a}$ & 4 \\
\hline
\end{tabular}

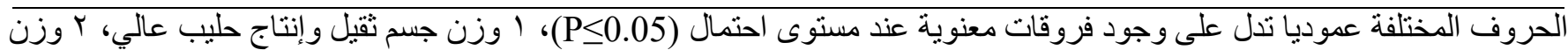

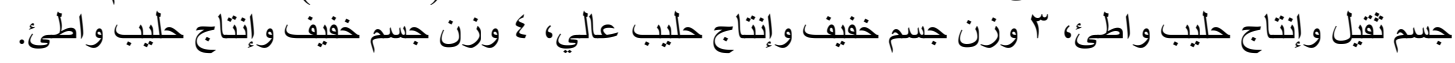

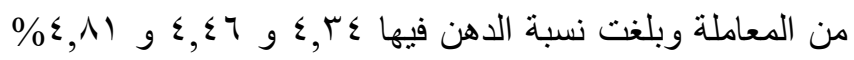

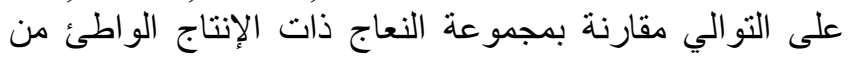

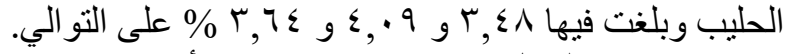

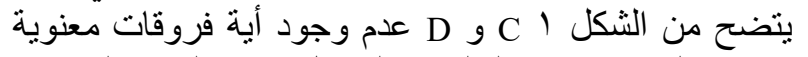

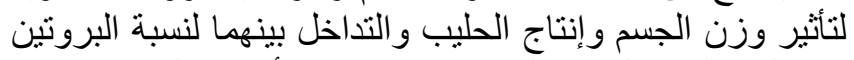
في حليب النعاج لجميع المعاملات في جميع أسابيع الدر اسة.
تبين من نتائج التحليل الإحصائي لبيانات تأثير وزن الجسم

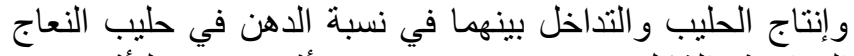

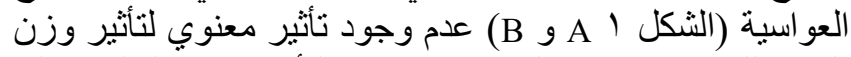

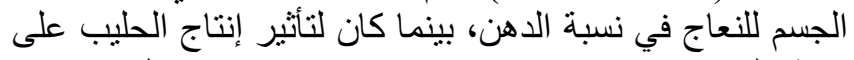

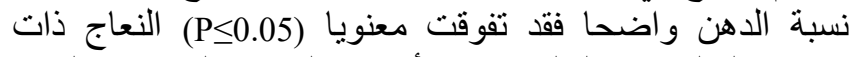
الإنتاج العالي من الحليب في الأسبوع الثاني والسادس والثنامن 
الجدول § : الكتوسط د الخطأ القياسي لنأثير وزن الجسم و إنتاج الحليب والتداخل بينهما في إنتاج الحليب اليومي (غم) للحملان العواسية

\begin{tabular}{|c|c|c|c|c|}
\hline \multicolumn{4}{|c|}{ الصفات } & \multirow{2}{*}{ المعاملات } \\
\hline الأسبوع الثامن & الأسبوع السادس & الأسبوع الرابع & الأسبو ع الثاني & \\
\hline & & & & تأثّير وزن الجسم \\
\hline $58.31 \pm 622.13 \mathrm{a}$ & $55.18 \pm 685.25 \mathrm{a}$ & $51.76 \pm 695.13 \mathrm{a}$ & $47.88 \pm 769.13 \mathrm{a}$ & ثقيل \\
\hline \multirow[t]{2}{*}{$34.65 \pm 493.13 \mathrm{~b}$} & $33.93 \pm 35.75 b$ & $31.26 \pm 506.38 \mathrm{~b}$ & $20.42 \pm 516.50 \mathrm{~b}$ & خفيف \\
\hline & & & & تأثيّير إنتاج الحليب \\
\hline $32.86 \pm 719.38 \mathrm{a}$ & $33.09 \pm 772.00 \mathrm{a}$ & $38.14 \pm 742.25 \mathrm{a}$ & $52.87 \pm 750.88 \mathrm{a}$ & عالي \\
\hline \multirow[t]{2}{*}{$24.24 \pm 395.88 \mathrm{~b}$} & $19.23 \pm 449.00 \mathrm{~b}$ & $26.83 \pm 459.25 \mathrm{~b}$ & $22.02 \pm 534.75 \mathrm{~b}$ & و واطئ - ل مئ \\
\hline & & & بسم و إنتاج الحليب & تأثثير التداخل بين وز \\
\hline $20.31 \pm 836.25 \mathrm{a}$ & $25.55 \pm 886.75 \mathrm{a}$ & $25.91 \pm 879.50 \mathrm{a}$ & $25.97 \pm 942.75 \mathrm{a}$ & 1 \\
\hline $32.59 \pm 408.00 \mathrm{c}$ & $28.29 \pm 483.75 \mathrm{c}$ & $33.15 \pm 510.75 \mathrm{c}$ & $23.25 \pm 595.50 \mathrm{~b}$ & 2 \\
\hline $17.75 \pm 602.50 \mathrm{~b}$ & $16.68 \pm 657.25 \mathrm{~b}$ & $13.48 \pm 605.00 \mathrm{~b}$ & $28.08 \pm 595.00 \mathrm{~b}$ & 3 \\
\hline $37.60 \pm 383.75 \mathrm{c}$ & $20.97 \pm 414.25 \mathrm{~d}$ & $35.04 \pm 407.75 \mathrm{~d}$ & $21.97 \pm 474.00 \mathrm{c}$ & 4 \\
\hline
\end{tabular}

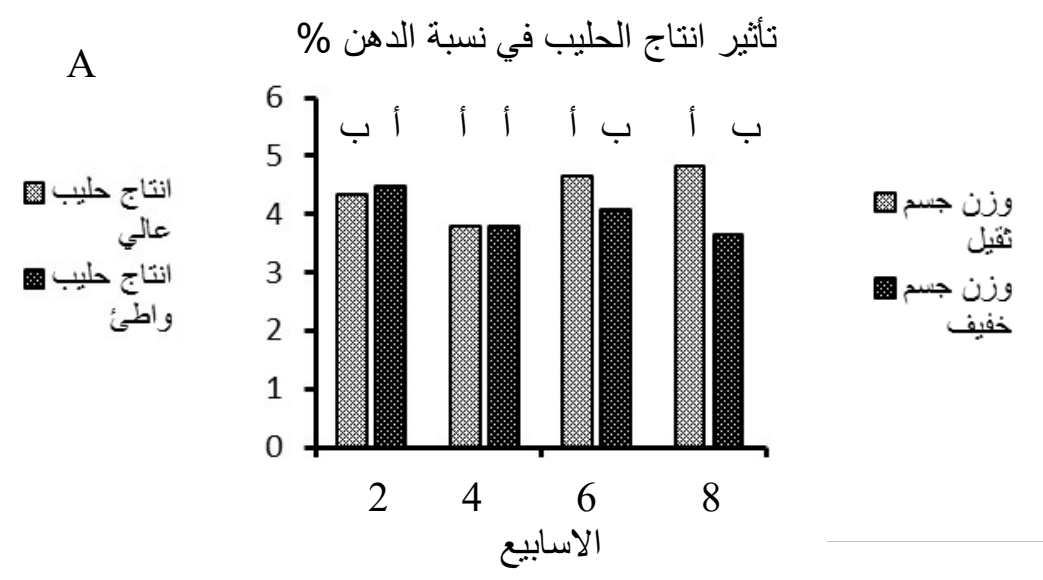

B تأثير وزن الجسم في نسبة الدهن
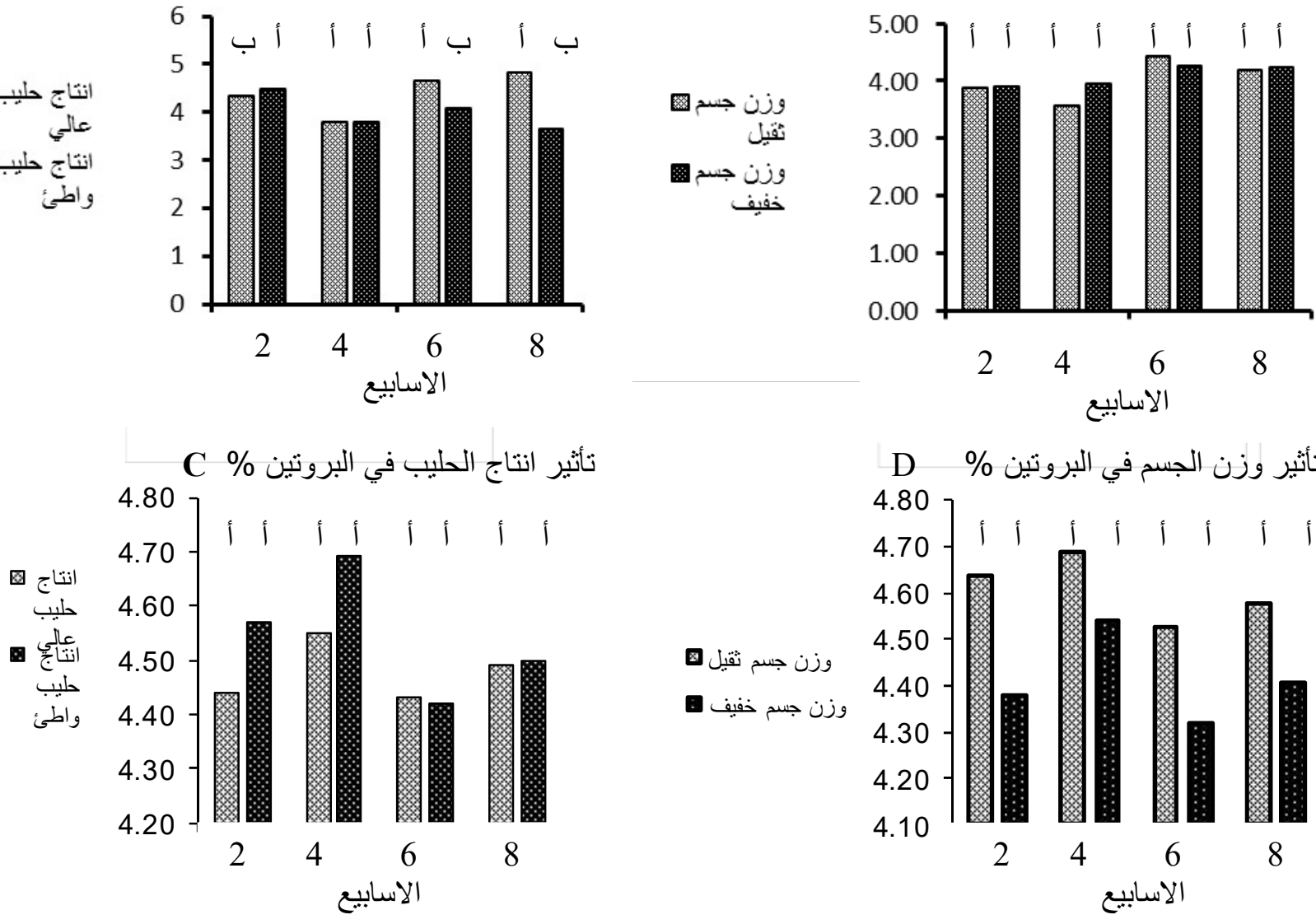

D ت أثثير وزن الجسم في البروتين

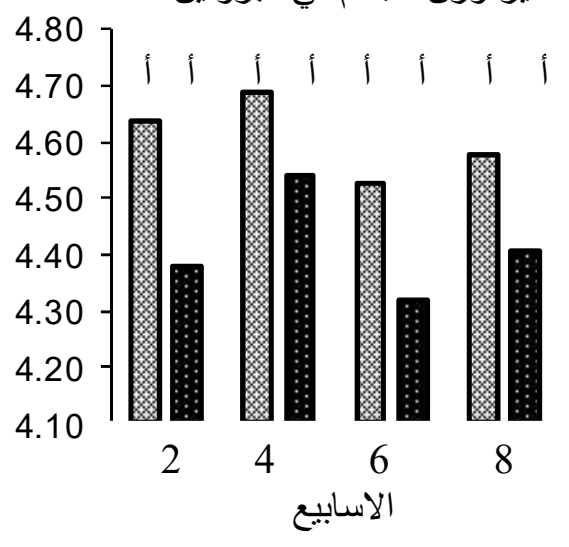

الثكل ا : تأثثر وزن الجسم وانتاج الحليب في نسبة الدهن و البروتين \% في حليب نعاج الدر اسة. 


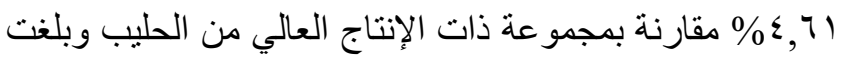

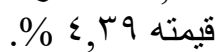

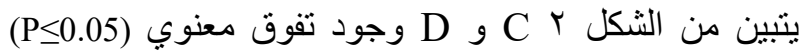
للمجموعة النعاج ذات الوزن الخفيف في نسبة المواد الصلبة

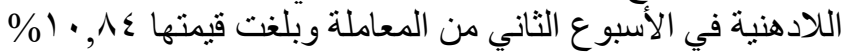

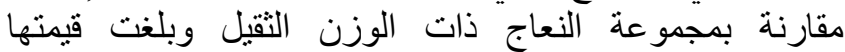

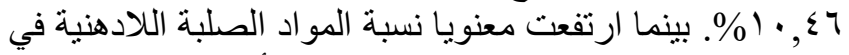

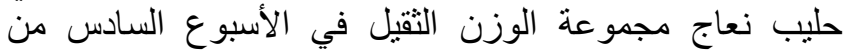

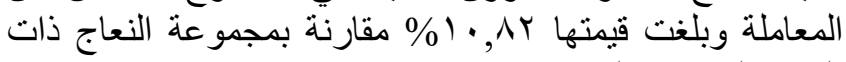

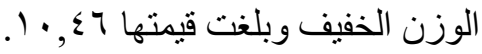
تاثثير انتاج الحليب في اللاكتوز\%

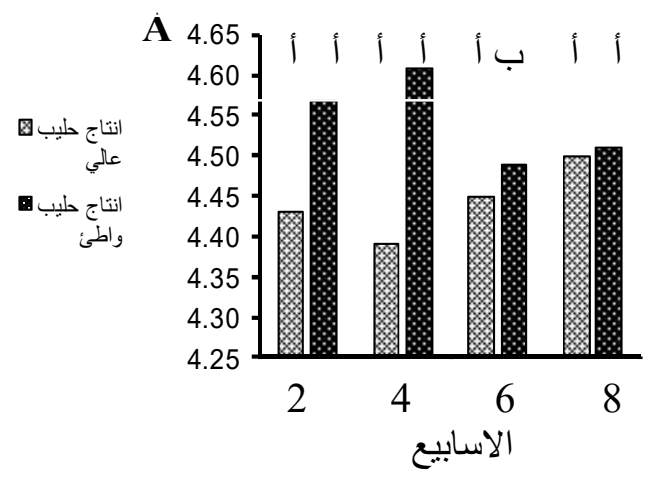

تاثير انتاج الحليب في المو اد الصلبة اللادهنية \%

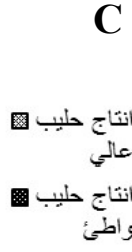

C

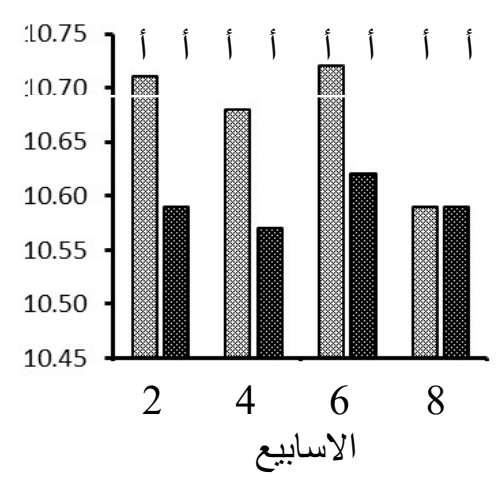

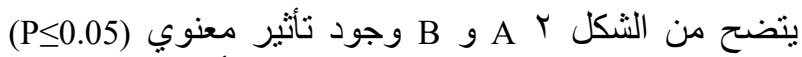

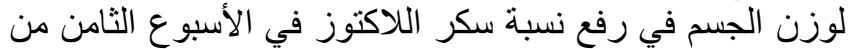

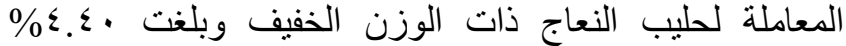

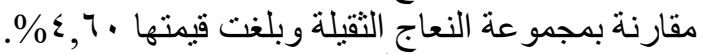

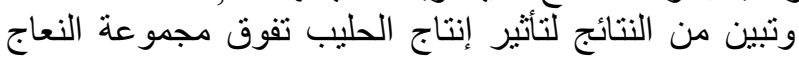

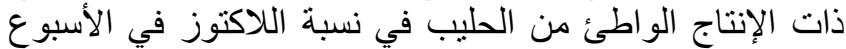

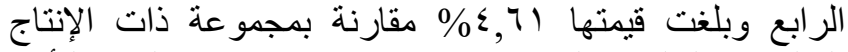

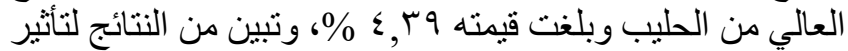

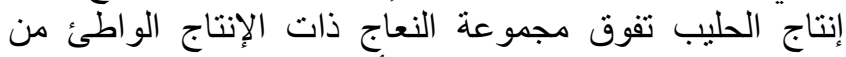
الحليب في نسبة اللاكتوز في الأسبوع الرابع والعباج الثت قيمتها

ت تاثير وزن الجسم في اللاكتوز

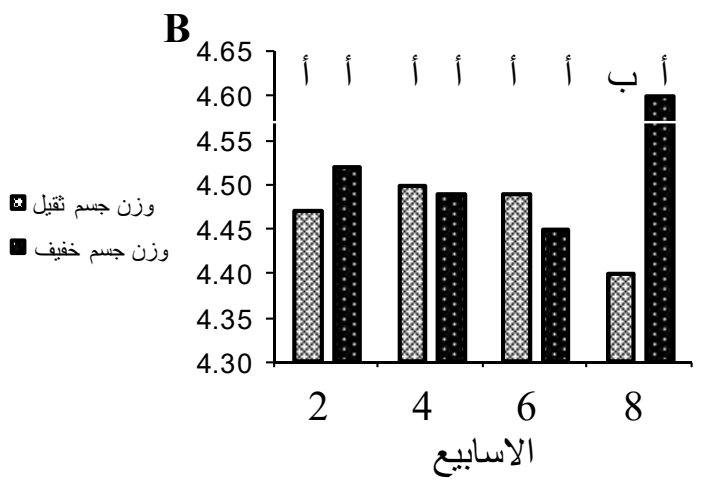

تاثثر وزن الجسم في المو اد الصلبة اللادهنية \%

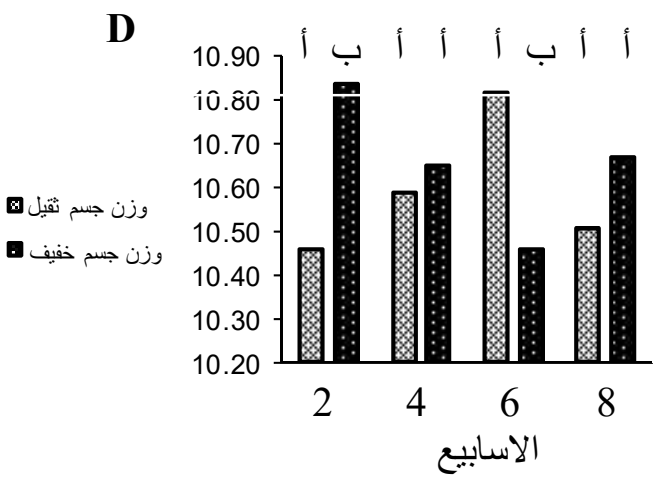

الثكل ץ : تأثير وزن الجسم و انتاج الحليب في نسبة اللاكتوز و المو اد الصلبة اللادهنية \% في حليب نعاج الدراسة.

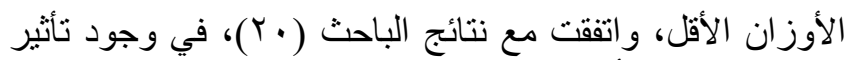

المناقثة

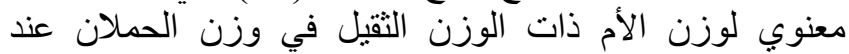

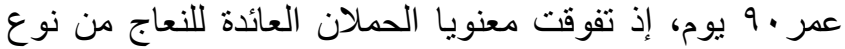

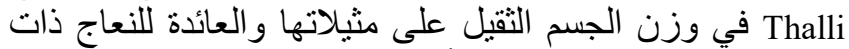

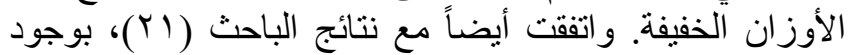
زيادة معنوية في أوزان الحملان التابعة للنعاج ذات الأوزان

يتبين من النتائج المتحصل عليها وجود ارتفاع معنوي في

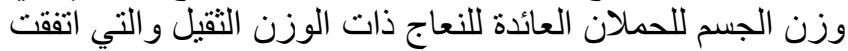

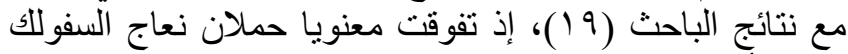
ذات الأوزان العالية في وزن الجسم مقارنة بحملان النعاج ذات التهات التهات 
الضرع لديها، مع وجود معامل ارتباط موجب للعامل الوراثي

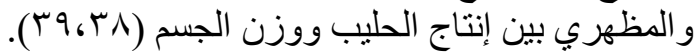

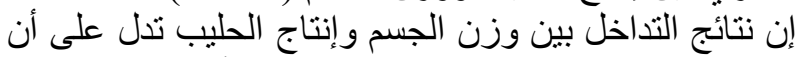

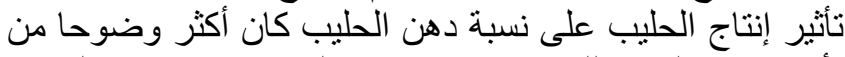

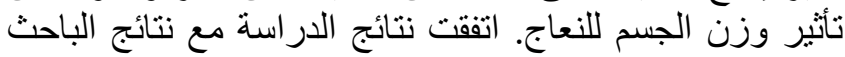

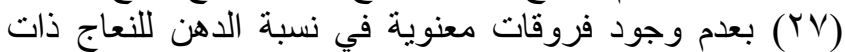

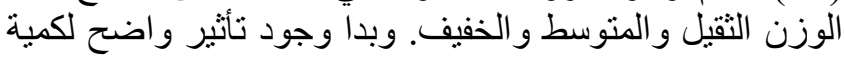

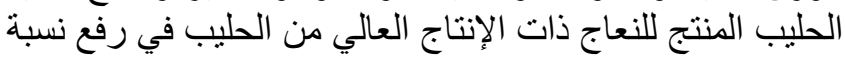

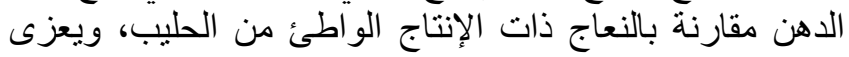

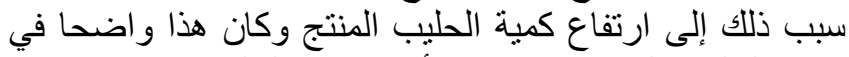

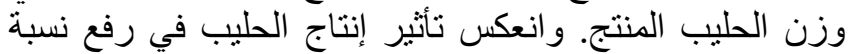

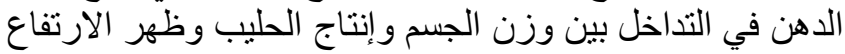

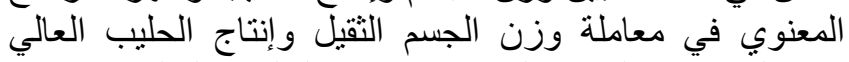

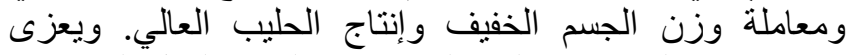

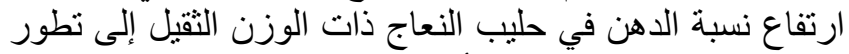

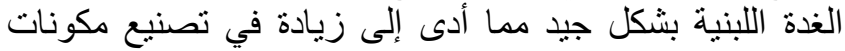
الحليب (ب9) (ب).

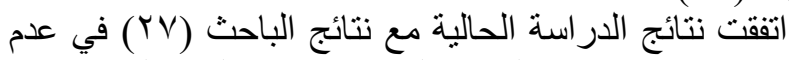

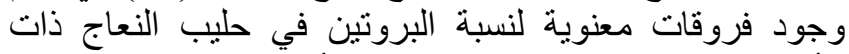

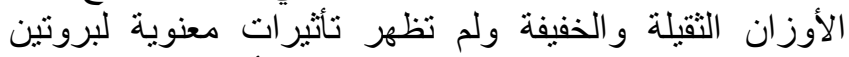
الحليب في معاملات الدر اسة، ربما يعود إلى أن احتياجات الطئة الطاقة كانت منيسرة لجميع المعاملات.

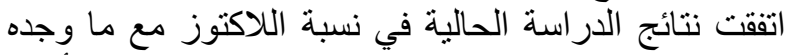

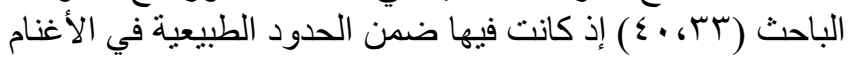

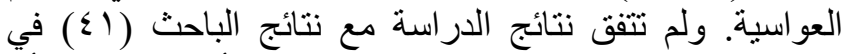

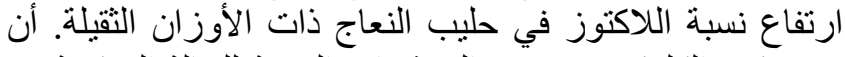

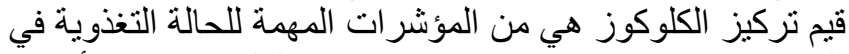

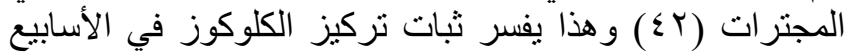

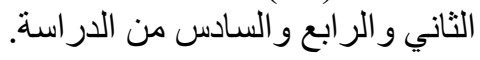

المصادر

1. Lafi SQ, Talafha AQ, Giadinis N, Kalaitzakis E, Ourliotis K, Panousis $\mathrm{N}$. Factors affecting the reproductive performance of Awassi sheep flocks in north-east of Jordan: An epidemiological study. Trop Anim Health Prod. 2009;41:1755-1764.

2. Thomson EF, Martini MA, Tutwiler RN. Sheep management practices in Iraq, Jordan and Syria: the case of reproduction and fertility. Aleppo, Syria: International Center for Agricultural Research in the Dry Areas (ICARDA). Integrated Natural Resource; 2003.

3. Juma KH, Al-Kass JE. Genetic and phenotypic parameters of some economic characteristics in Awassi sheep of Iraq: A review. Egyptian J Sheep Goat Desert Anim Sci. 2006;1(1):15-29.

4. Afolayan RA, Adeyinka IA, Lakpini CMA. The estimation of live weight from body measurements in Yankasa sheep. Czech J Anim Sci. 2006;51:343-348.

5. Ozcan M, Altinel A, Yilmaz A, Gunes H. Studies on the possibility of improving lamb production by two-way and three-way crossbreeding with German Black Headed Mutton, Kivircik and Chios sheep breeds. Turkish J Vet Anim Sci. 2001;25:687-694.
العالية من نوع Karaman مقارنة بحملان النعاج الأقل وزنا،

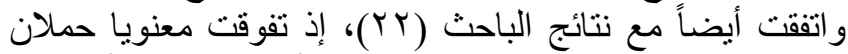

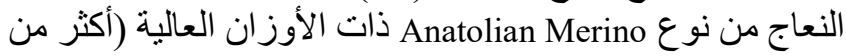

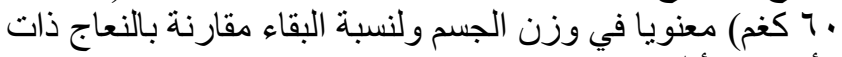

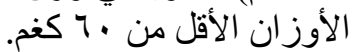
إن ارتفاع أوزان الحملان العثان العائدة للنعاج ذات الأوزان الثقيلة

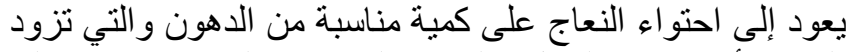

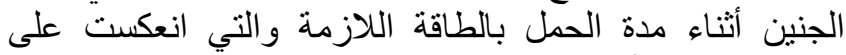

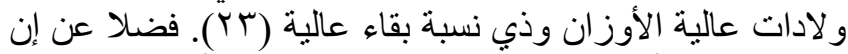

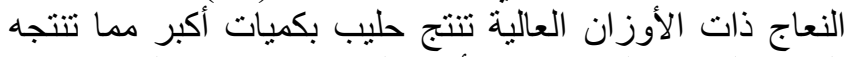

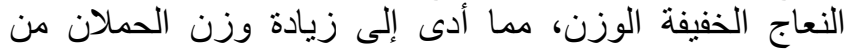

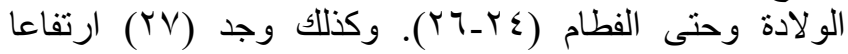

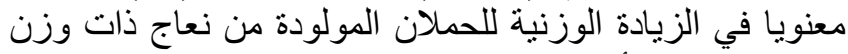

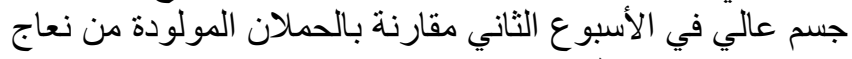

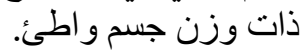
إن حالة الجسم الجيدة عند الولادئ لادة للنعاج تتعكس في تربية

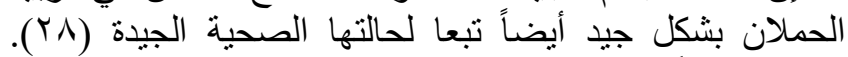

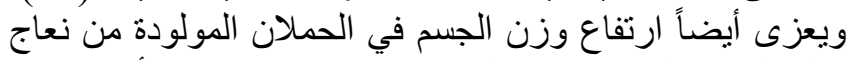

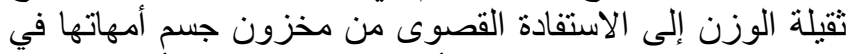

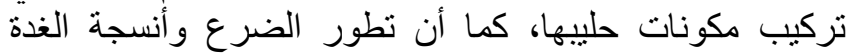

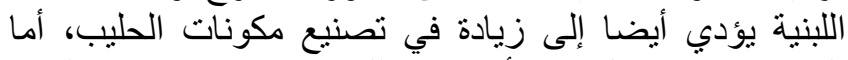

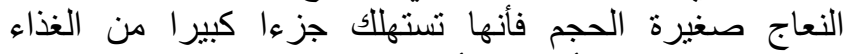

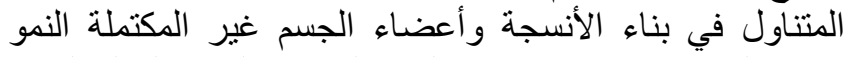

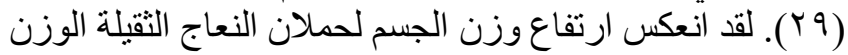

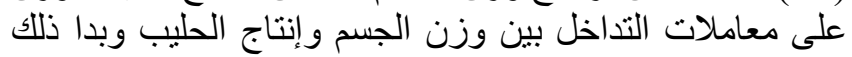

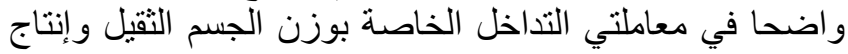

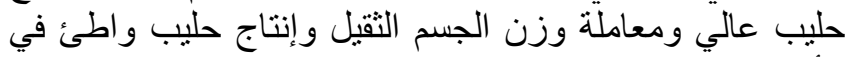

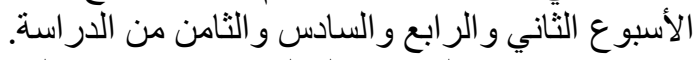

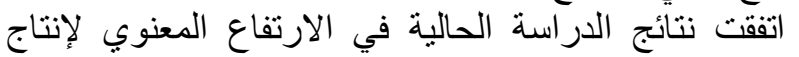

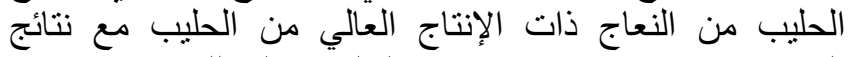

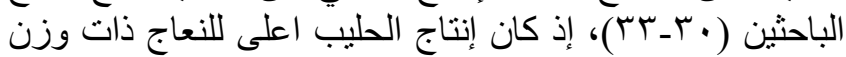

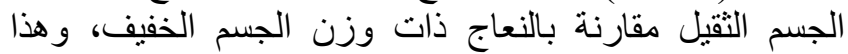

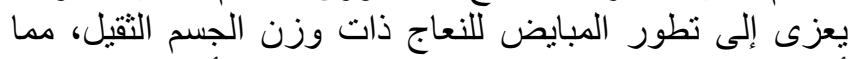

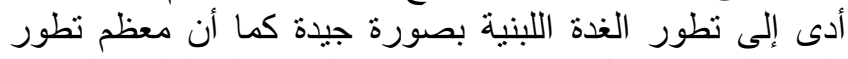

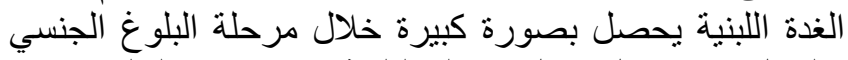

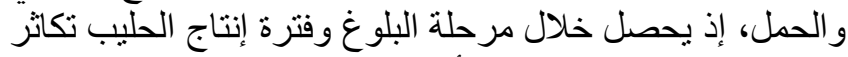

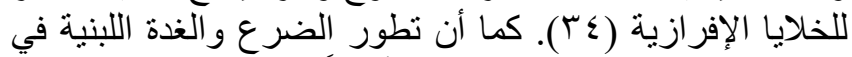

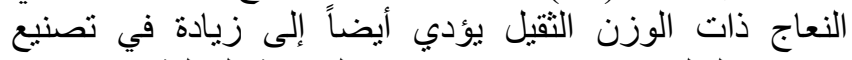

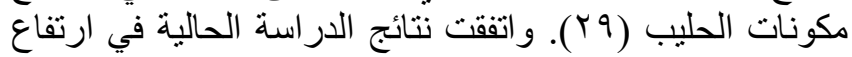

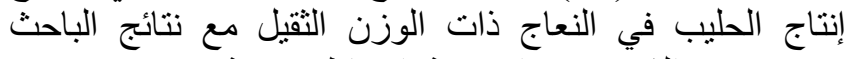

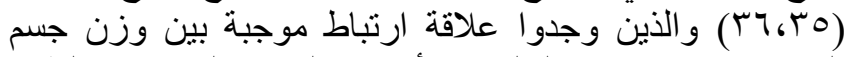

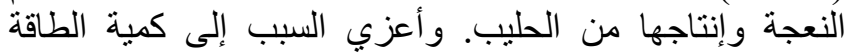

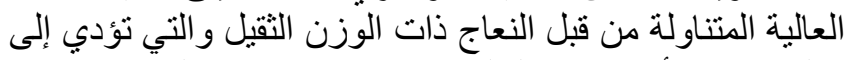
تخليق كمية أكبر من الحليب (YV) بالإضافة إلى العى كبر حجم 
25. Ivanova T, Metodiev N, Raicheva E. Effect of the genealogic line on milk production and prolificacy of the ewes from synthetic population Bulgarian milk. Bulgarian J Agri Sci. 2013;19:158-162.

26. Barać Z, Mioč B, Špehar M. The effect of lactation stage and parity, lambing season, and herd on fat and protein content in Pag sheep. Mljekarstvo. 2013;63:81-90.

TV

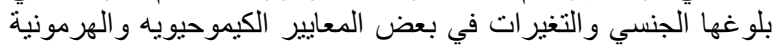

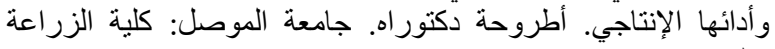

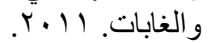

28. Mathias HC, Shackell GH, Greer GJ, Bryant AI, Everett JM. Ewe body condition score and the effect on lamb growth rate. Proc New Zealand Soc An. 2013;73:131-135.

29. Sevi A, Taibi L, Albenzio M, Muscio A, AnnicchiricoG. Effect of parity on milk yield, composition, somatic cell count, renneting parame ters and bacteria counts of Comisana ewes. Small Ruminant Rese Arch. 2000;37(1-2):99-107.

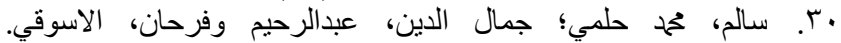

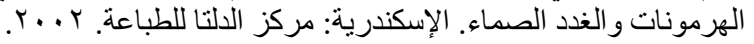

31. Macdonald LE, Pineda MH, Doley MP. Veterinary endocrinology and reproduction. $5^{\text {th }}$ ed. USA: Iowa State Press; 2003.

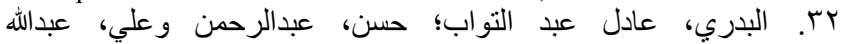

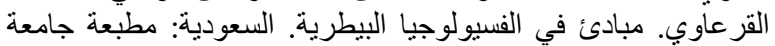

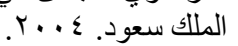

rr. الدباغ، صميم فخري حمد صدالح. مقارنة الاداء الإنتاجي والفسلجي

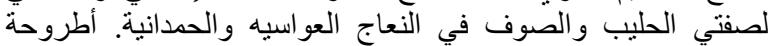

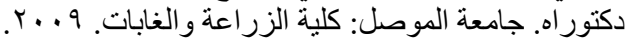

34. Norgaar JV, Nielsen MO, Theil PK, Sorensen T, Safayi S, Sejrsen K. Development of mammary gland of fat sheep suhnitted to restricted feeding during late pregnancy. Small Rumin Res. 2008;76:155-165.

35. Berry DP, Buckley F, Dillon P. Body condition score and live-weight effects on milk production in Irish Holstein- Friesian dairy cows. Animal. 2007;1:1351-1359.

36. Van - der Linden DS, Kenyon PR, Blair HT, Lopes N, Jenkinson CMC, Peterson SW, Mackenzie DDS. Effect of ewe size and nutrition on fetal mammary gland development and lactational performance of offspring at their first lactation. J Anim Sci. August 2009;14:1-32.

37. Godfrey RW, Gray ML, Collins JR. Lamb growth and milk production of hair and wool sheep in a semi-arid tropical environment. Small Rumin Res. 1997;24:77-83.

38. Veerkamp RF. Selection for economic efficiency of dairy cattle using information on live weight and feed ntake: a review. J Dairy Sci. 1998;81:1109-1119.

39. Veerkamp RF, Thompson R. A covariance function for feed intake, live weight, and milk yield estimatedusing a random regression model. J Dairy Sci. 1999;82:1565-1573.

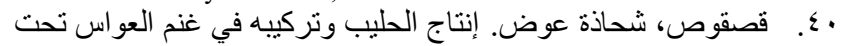

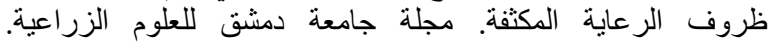

.7_ 7 ـ $10 \leqq 1999$

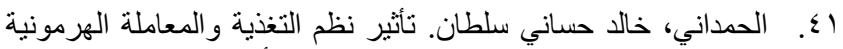

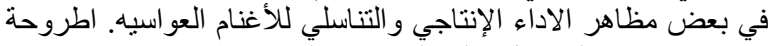

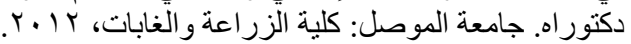

42. Bertoni G, Lombardelli R, Biffi R. Some endocrinological and metabolic variations in Sarda sheep during late pregnancy and early lactation. 1999;82:15-25.
7 ا. ابو النجا، عادل. نظم تعدد الولادات دليل عن تحسين التناسل في الأغنام

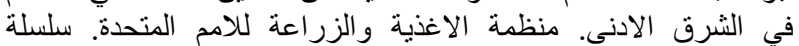

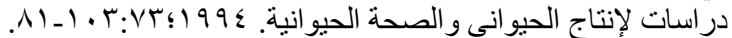

7. Boujenane IG, Bardford GE, Femula TR. Inheritance of litter size and its component in crosses between the Dman and Sardi breed of sheep. J Anim Sci. 1991;69:517-524.

8. Maria GA, Boldman KG, Van Vleck LD. Estimates of variances due to direct and maternal effects for growth traits of Romanov sheep. J Anim Sci. 1993;71:845-849.

9 . . الراوي، الهام عبد الحميد عبد المجيد. تأثنير استخدام المستوى ألبروتيني

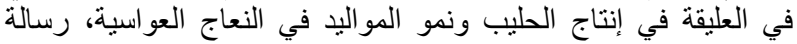

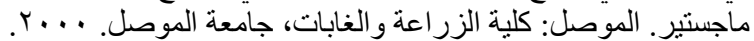

10. Mellor DJ. Nutritional and placental determinants of fetalrowth-rate in sheep and consequences for the newborn lamb. $\mathrm{Br}$ Vet $\mathrm{J}$. 1983;139:307-324.

11. Van der Linden DS, Kenyon PR, Blair HT, Lopez VN, Jenkinson CMC, Peterson SW, Mackenzie DDC, Martini EF. Effects of ewe size and nutrition on fetal mammary glandevelopmentand lactational performance of offspring at their first lactation1. J Anim Sci. 2014;87:3944-3954.

12. Pulina G, Nudda A, Battacone G, and Cannas, A. Effects of nutrition on the content of fat, protein somatic cells, aromatic compounds, and undesirable substances in sheep milk. Anim Feed Sci Technol. 2006;131:255-291.

13. Walker GP, Dunshea FR, Doyle PT. Effects ofnutrition and management on the production and composition of milk fat and protein: A review. Aust J Agric Res. 2004;55:1009-1028.

14. Jenkinson CMC. The pattern and regulation of mammary gland development during fetal life in the sheep [PhD Thesis]. New Zealand: Massey University. 2003.

10. الخواجه، علي كاظم؛ الهام عبد الله وسمير عبد الأحد. تأثير استخدام

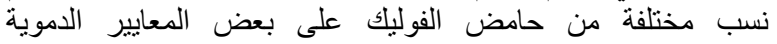

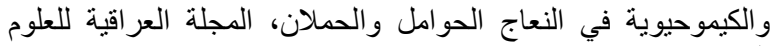

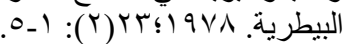

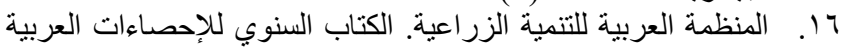
الزر اعية. الخرطوم،

17. Statistical Analysis Systems User's Guide (SAS). North Carolina: SAS Institute Inc. 2003.

18. Steel RGD, Torrie JH. Principles procedures of statistics. New York: McGraw - Hill Book Company. 1960. 481 p.

19. Ptacek M, Duchacek J, Stadnik L, Beran J, Stolc L. Effects of ewes' live weight and backfat thickness at mating on fertility and production performance in Suffolk sheep and their crosses. Bulg J Agric Sci. 2014;20:1261-1267.

20. Hussain A, Akhtar P, Ali S, Younas M, Yaqoob M, Babar ME, Javed $\mathrm{K}$, Shakoor A. Factors influencing body weights at different ages in thalli sheep. J Anim Plan Sci. 2013;23(1):1-6.

21. Akta AH, Dogan S. Effect of live weight and age of Akkara- ${ }^{-}$man ewes at mating on multiple birth rate, growth traits, and survival rate of lambs, Turkish J Vet Anim Sci. 2014;38:176-182.

22. Aktas H, Dursun S, Doganl S, Kiyma Z, Demircil U, Halicil H. Effects of ewe live weight and age on reproductive performance, lamb growth, and survival in Central Anatolian Merino sheep. Arch Anim Breed. 2015;58:451-459.

23. Sawalha R, Conington MJ, Brotherstone S, Villanueva B. Analyses of lamb survival of Scottish Blackface sheep. Anim. 2007;1:151-157.

24. Snowder GD, Glimp HA. Influence of breed, number of suckling lambs, and stage of lactation on ewe milk production and lamb growth under range conditions. J Anim Sci. 1991;69:923-930 